\title{
Internukleäre Ophthalmoplegie bei MS
}

\section{Ein 45-jähriger Mann mit bekannter multipler Sklerose stellte sich mit zunehmender Schwäche im rechten Bein und Doppelbildern vor. Bei der neurologischen Untersuchung stellte man eine horizontale Diplopie beim Seitwärtsblicken auf beiden Augen fest.}

- Der Patient wies ein Adduktionsdefizit am rechten Auge und einen Nystagmus am linken Auge beim Blick nach links auf (Abb. A). Beim Blick nach rechts zeigten sich auch eine Adduktionsschwäche des linken Auges und ein Nystagmus am rechten Auge (Abb. B). Beim Blick nach oben (Abb. C) und nach unten (Abb. D) sowie beim Geradeausblick (Abb. E) waren keine pathologischen Befunde feststellbar.
Die internukleäre Ophthalmoplegie ist durch eine gestörte horizontale $\mathrm{Au}$ genbeweglichkeit charakterisiert und beruht auf einer Läsion des Fasciculus longitudinalis medialis, ein Fasertrakt, der am Abducens-Kern in der Pons entspringt und zum kontralateralen Oculomotorius-Kern im Hirn zieht. Dies führt zu einem Adduktionsdefizit beim Versuch des Blicks zur Seite.

Jede Läsion im Bereich des Hirnstammes kann den Fasciculus longitudinalis medialis unterbrechen und die horizontale Augenbewegung unmöglich machen, der häufigste Grund sind aber die demyelinisierenden Vorgänge bei der multiplen Sklerose.

Trotz i.v.-Therapie mit Glukokortikoiden waren die Defizite bei diesem Patienten nicht reversibel. Bei einer Kon- trolluntersuchung zwei Monate später hatte sich zwar das Gangbild gebessert, die Defizite bei der horizontalen Augenbeweglichkeit blieben aber bestehen.

\section{Kommentar}

Leider bestätigt dieser Fall das von Ärzten anderer Fachrichtungen häufig gehörte (Vor-)Urteil, dass die Neurologie mit relativ einfachen Mitteln unter Anwendung umfangreicher topischer und funktioneller Kenntnisse zwar über ein starkes diagnostisches Bein verfügt, das therapeutische Bein aber ziemlich dürftig ausgebildet ist.

H. S. FÜESSL =

- G.W. Hassen und N. Bhardwaj (Mount Sinai School of Medicine, Lutheran Medical Center Brooklyn, NY): Bilateral internuclear ophthalmoplegia in multiple sclerosis. New Engl. J. Med. 2013; 368: e3

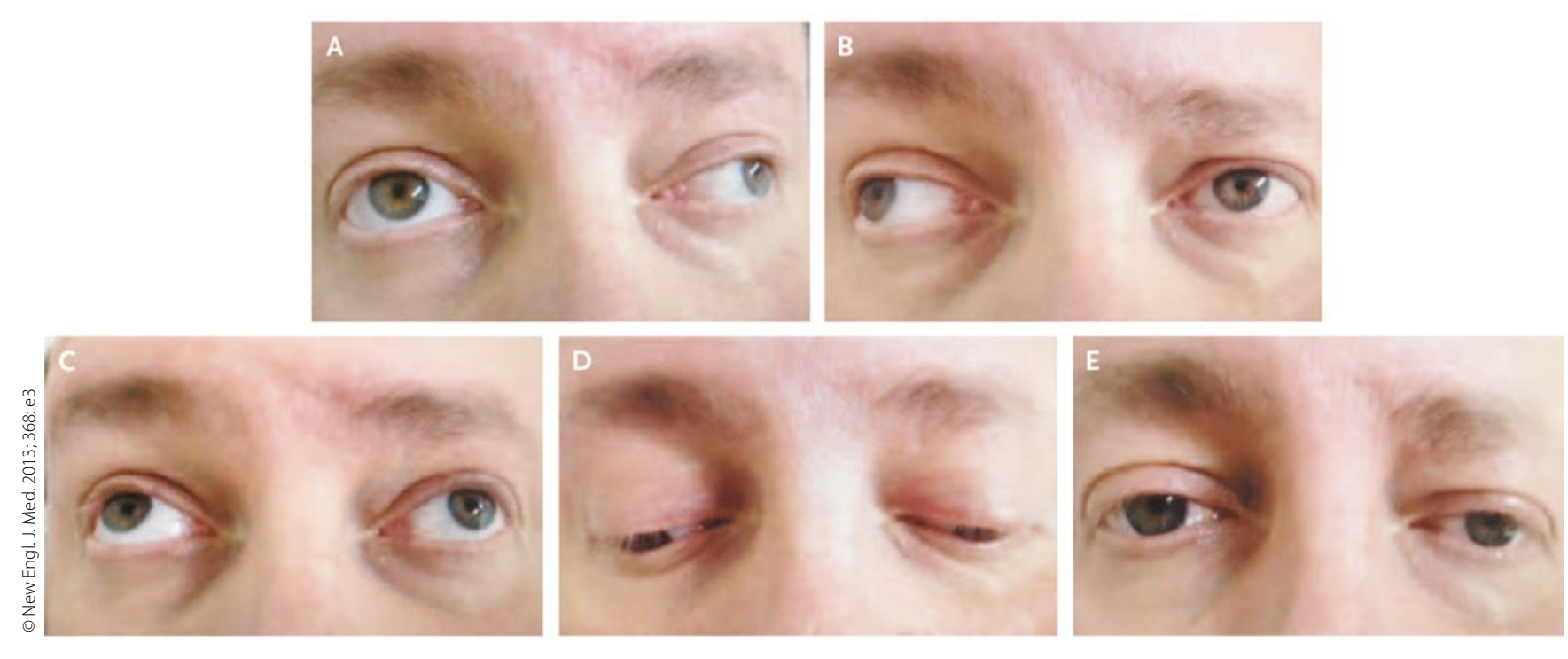

Patient mit MS: Adduktionsdefizit am rechten Auge und ein Nystagmus am linken Auge beim Blick nach links (A); Adduktionsschwäche des linken Auges und ein Nystagmus am rechten Auge beim Blick nach rechts (B); Keine Auffälligkeiten beim Blick nach oben (C), unten (D) und geradeaus (E). 